\title{
Northern Apennines as centre of speciation: a new Verdanus species group (Hemiptera, Cicadomorpha, Cicadellidae) from Italy and its phylogenetic relationships with $V$. bensoni and the $V$. limbatellus group
}

\author{
ADALGISA GUGLIELMINO ${ }^{1} \&$ CHRISTOPH BÜCKLE ${ }^{2}$ \\ ${ }^{1}$ Department of Plant Protection, University of Tuscia, Via S. Camillo de Lellis, 01100 Viterbo, Italy \\ ${ }^{2}$ Neckarhalde 48, 72070 Tübingen, Germany
}

\begin{abstract}
A small sector of Northern Apennines - the Tuscan-Emilian Apennines - constitutes an interesting diversity centre of a new Verdanus species group closely related to $V$. bensoni and the $V$. limbatellus group. It consists of three species: $V$. tyrannus sp. nov., V. saurosus sp. nov. and V. rosaurus sp. nov., the latter with two subspecies, V. rosaurus rosaurus ssp. nov. and $V$. rosaurus rex ssp. nov., which doubtless form a monophyletic group (V. rosaurus group). Data on their distribution, ecology and life cycle are added to their original descriptions. The new taxa live allopatrically in a very restricted area and thus occupy a distribution gap of another species group of Verdanus, the V. abdominalis group, present in Italy in the mountain regions of the Alps and Central and Southern Apennines. A hypothesis of the origin of the new taxa is presented based on the ecological conditions in the Tuscan-Emilian Apennines during the last Postglacial period and on the limited dispersal ability of these normally brachypterous insects. Possible synapomorphic characters and phylogenetic relationships of the new taxa with each other and with $V$. bensoni (China) and the V. limbatellus group (V. limbatellus (Zetterstedt), V. kyrilli (Emeljanov), V. sichotanus (Anufriev), V. kaszabi (Dlabola)) are discussed and a cladistic analysis is conducted. Comparing $V$. bensoni and the $V$. limbatellus group on the one hand and the $V$. rosaurus group on the other, some morphological characters appear to change often in parallel on the same paths, independently from the phylogenetic hypothesis. Remarkably, within the same morphological characters the range of variation among species inhabiting the comparatively minute area of the Tuscan-Emilian Apennines is similar to that found among other taxa distributed across vast areas of northern and central Eurasia.
\end{abstract}

Key words: Auchenorrhyncha, biogeography, Deltocephalinae, ecology, evolution, Paralimnini, phylogeny, taxonomy

\section{Introduction}

The genus Verdanus was established by Oman (1949) for Deltocephalus evansi Ashmead, 1904 (the type species). He distinguished the new taxon from the genus Diplocolenus on the base of aedeagal differences. Several authors (i.e. Ribaut, 1952; Nast, 1972, 1987; Knight, 1974; della Giustina, 1989) considered it a subgenus of Diplocolenus.

Verdanus is a Holarctic genus with prevalence of species occuring only in the Palaearctic Region (Knight, 1974). Presently, in Europe, this genus consists of two subgenera, Verdanus and Erdianus, including ten and nine species respectively (Hoch, 2004). In Italy are recorded: Verdanus (Verdanus) abdominalis (Fabricius), $V$. (Verdanus) laetitiae (Servadei), V. (Verdanus) monticola (Linnavuori), V. (Erdianus) nigricans (Kirschbaum) and V. (Erdianus) penthopitta (Walker) (D'Urso, 1995); the record of the last species is doubtful as it is based on only one very old notice (Vismara, 1878: Piemonte, as Acocephalus sudeticus Kolenati, see Servadei, 1967).

The species of the subgenus Verdanus s. str. living in Italy all belong to the V. abdominalis group: Verdanus monticola is widely distributed and quite common throughout the Central Apennines on meadows and 